\title{
Pembuatan Sabun Mandi Padat dari VCO yang Mengandung Karotenoid Wortel
}

\author{
Raymon Langingia*, Lidya I. Momuata, Maureen G. Kumaunanga \\ aJurusan Kimia, FMIPA, Unsrat, Manado
}

KATA KUNCI
Apa
Ini
Itu

\section{KE YW O R D}

VCO

Bar soap

Carotenoid

carrot

\begin{tabular}{l} 
A B S T R A K \\
Penelitian ini bertujuan menentukan konsentrasi NaOH yang \\
optimum untuk direaksikan dengan VCO mengandung karotenoid wortel \\
guna menghasilkan sabun mandi padat yang memenuhi kualitas Standar \\
Nasional Indonesia (SNI) No. O6-3532-1994. Pembuatan sabun mandi \\
diawali dengan penentuan bilangan penyabunan, yang digunakan pada \\
perhitungan konsentrasi NaOH, yakni $25 \%$, 30\% dan 35\%. Sabun mandi \\
padat yang dihasilkan diuji kualitasnya menurut SNI No. 06-3532-1994. \\
Bilangan penyabunan dari VCO mengandung karotenoid wortel diperoleh \\
sebesar 173,18 mg. Sabun mandi pada semua konsentrasi NaOH \\
memenuhi SNI untuk uji jumlah asam lemak, alkali bebas dan asam \\
lemak bebas. Untuk kadar air, sabun yang memenuhi SNI ada pada \\
konsentrasi NaOH 35\%, dan minyak mineral pada konsentrasi NaOH $30 \%$. \\
Sabun pada semua konsentrasi NaOH tidak memenuhi SNI untuk uji \\
lemak netral. Penelitian ini menyimpulkan bahwa belum diperoleh \\
konsentrasi NaOH yang optimum untuk pembuatan sabun mandi padat \\
dari VCO mengandung karotenoid wortel yang memenuhi kualitas SNI No. \\
O6-3532-1994. Sabun mandi yang mendekati kualitas SNI ada pada \\
konsetrasi NaOH $30 \%$ dan $35 \%$. \\
\hline A B S T R A C T \\
The purpose of this research was to determine the optimum \\
consentration of NaOH needed for the reaction with VCO containing carrot \\
carotenoids during the bar soap making qualified to SNI No. O6-3532- \\
1994. Three types of bar soap were made from the VCO and NaOH with \\
different concentrations that were $25 \%$, $30 \%$ and $35 \%$ based on the \\
saponification value of the soap which was 173.18 mg. The total fatty \\
acids content, free alkali content, free fatty acids content, water content, \\
mineral oil content and neutral fat content of the three types of soap were \\
measured according to the SNI. The results showed that the total fatty \\
acids content, free alkali content and free fatty acids content of all types of \\
soap met the SNI standards. However, only the water content of soap with \\
35\% of NaOH and the mineral oil content of soap with $30 \%$ of NaOH that \\
met the SNI standards. The results also showed that there was no type of \\
soap that met the SNI standard for the neutral fat content.. \\
\hline
\end{tabular}

Pemanfaatan wortel dalam pembuatan minyak kelapa murni (virgin coconut oil, VCO) telah dilakukan oleh Makalalag (2010). Pada penelitian tersebut, VCO dibuat dari daging kelapa segar (non-kopra), tanpa pemanasan. VCO yang dihasilkan berwarna jingga, seperti warna wortel, yang disebabkan oleh terlarutnya komponen karotenoid dari wortel ke dalam VCO yang dihasilkan. VCO yang mengandung karotenoid wortel tersebut dapat digunakan untuk membuat beberapa produk turunan, seperti sabun

*Corresponding author: Jurusan Kimia FMIPA UNSRAT, Jl. Kampus Unsrat, Manado, Indonesia 95115; Email address: raymon.langingi@gmail.com Published by FMIPA UNSRAT (2012) 
mandi. Sabun mandi merupakan salah satu produk turunan dari minyak. Sabun mandi adalah produk yang dihasilkan dari reaksi antara minyak dan atau lemak dengan basa $\mathrm{KOH}$ atau $\mathrm{NaOH}$. Sabun mandi adalah senyawa natrium atau kalium dengan asam lemak dari minyak nabati dan atau lemak hewani dan berbentuk padat, lunak atau cair, berbusa, digunakan sebagai pembersih, dengan menambahkan zat pewangi, dan bahan lainnya yang tidak membahayakan kesehatan (Badan Standarisasi Nasional, 1994). Alkali yang digunakan pada penelitian ini adalah larutan $\mathrm{NaOH}$ yang dapat membuat sabun menjadi padat.

Pada penelitian ini, sabun mandi padat dibuat dengan memanfaatkan VCO yang mengandung karotenoid wortel. Secara ideal, sabun mandi padat memiliki kekerasan yang akan memberikan busa yang cukup (yaitu, perilaku sebagai agen pembusa), untuk meningkatkan kemampuan membersihkan dari sabun (Brown et al., 2011). Sejauh ini belum diperoleh informasi mengenai pemanfaatan VCO yang mengandung karotenoid wortel dalam pembuatan sabun mandi padat, teristimewa informasi mengenai konsentrasi $\mathrm{NaOH}$ yang dibutuhkan untuk direaksikan dengan VCO tersebut sehingga menghasilkan sabun mandi padat yang berkualitas menurut Standar Nasional Indonesia (SNI) untuk sabun mandi. Untuk itulah penelitian ini dilakukan, guna menentukan konsentrasi $\mathrm{NaOH}$ yang dibutuhkan untuk membuat sabun mandi padat yang berkualitas menurut SNI No. 06-35321994.

\section{Metode}

\subsection{Alat dan Bahan}

Alat yang digunakan berupa timbangan analitik, gelas piala, penangas air, pengaduk gelas, oven, corong pemisah, labu erlenmeyer, pendingin tegak, biuret, mikro biuret, tabung reaksi, wadah sabun, blender, botol timbang. Bahan dasar pembuatan minyak kelapa adalah daging buah kelapa yang dijual di pasar lokal, wortel lokal, $\mathrm{NaOH}, \mathrm{H}_{2} \mathrm{SO}_{4} 20 \%$, metil jingga 0,05\%, mikro parafin, dan petroleum eter.

\subsection{Metode}

\subsubsection{Pembuatan Santan}

Sebanyak 10 butir kelapa disiapkan. Daging kelapa yang telah diparut, dicampur dengan air panas bersuhu $70{ }^{\circ} \mathrm{C}$ dengan perbandingan 1:1 (1 gram daging kelapa parut : $1 \mathrm{~mL}$ air) dalam baskom. Setelah daging kelapa diperas dengan kain dan disaring dengan saringan plastik, santan yang diperoleh kemudian didiamkan selama 2 jam untuk memisahkan krim dan skim. Krim yang banyak mengandung lemak dicampur dengan ekstrak wortel untuk pembuatan VCO mengandung karotenoid wortel.

\subsubsection{Pembuantan Ekstrak Wortel}

Wortel dicuci bersih, dipotong dan dihaluskan dengan juice extractor hingga diperoleh ekstrak wortel. Ekstrak wortel siap dicampur dengan krim santan kelapa.

\subsubsection{Pembuatan VCO Mengandung Karotenoid Wortel}

Ekstrak wortel sebanyak $300 \mathrm{~mL}$ ditambah dengan krim santan sebanyak $700 \mathrm{~mL}$ hingga volume total campuran $1000 \mathrm{~mL}$ (konsentrasi ekstrak wortel $30 \%)$ dalam wadah plastik berkeran. Campuran diaduk dan didiamkan selama 18 jam. Selanjutnya dilakukan pemisahan antara air pada lapisan bawah dengan minyak dan blondo pada lapisan atas, dengan membuka keran pada bagian wadah. Untuk memisahkan minyak dari blondo dilakukan sentrifugasi pada kecepatan 3000 rpm, selama 15 menit. Hasilnya blondo mengendap pada dasar tabung sementara minyak berada pada lapisan atas. Minyak yang diperoleh berupa VCO mengandung karotenoid wortel digunakan untuk pembuatan sabun mandi padat.

\subsubsection{Penentuan Bilangan Penyabunan}

Sebanyak 2,5 gram VCO yang mengandung karotenoid wortel dalam erlenmeyer $250 \mathrm{~mL}$, ditambahkan $25 \mathrm{~mL} \mathrm{NaOH} \mathrm{0,5} \mathrm{M.} \mathrm{Blankonya} \mathrm{juga}$ dibuat (pengerjaannya sama dari awal, tetapi tanpa menggunakan sampel minyak). Baik bahan percobaan maupun blanko dibuat duplo (2x ulangan). Kemudian direfluks sampai penyabunan sempurna (kira-kira 30 menit). Reaksi penyabunan selesai jika tetesan hasil refluks dalam tabung reaksi berisi air berwarna bening. Setelah didinginkan, hasil refluks ditambahkan 2 tetes indikator fenolftalein dan dititrasi dengan $\mathrm{HCl}$ sampai warnanya tepat hilang. Setelah itu bilangan penyabunan ditentukan berdasarkan rumus:

\subsubsection{Pembuatan Sabun}

Sebanyak 20 gram VCO yang mengandung karotenoid wortel direaksikan dengan $\mathrm{NaOH}$ sedikit demi sedikit. Jumlah dan konsentrasi yang direaksikan, ditentukan berdasarkan bilangan penyabunan VCO yang mengandung karotenoid wortel. Sabun yang dihasilkan dibuat dalam 3 variasi konsentrasi $\mathrm{NaOH}$, yakni 25\%, 30\%, 35\%, yang dihitung berdasarkan bilangan penyabunan dan banyaknya air yang dibutuhkan untuk membuat masing-masing konsentrasi $\mathrm{NaOH}$. Setiap perlakuan konsentrasi $\mathrm{NaOH}$ dibuat 3 kali ulangan. Setelah VCO direaksikan dengan $\mathrm{NaOH}$, campuran diaduk perlahan-lahan hingga mengental dan homogen. Sabun mandi yang dihasilkan dituang dalam wadah bersih yang telah disiapkan dan didiamkan selama 4 minggu. Selanjutnya sabun mandi yang dihasilkan diuji kualitasnya berdasarkan SNI No. 06-3532-1994.

\section{Hasil dan Pembahasan}

\subsection{Karakteristik Sabun}

Bilangan penyabunan dari VCO yang mengandung karotenoid wortel diperoleh sebesar 173, 18. Ketiga sabun mandi padat yang dihasilkan dari konsentrasi $\mathrm{NaOH}$ berbeda, memiliki berat rata-rata 29 gram dan berwarna jingga. Warna jingga pada sabun merupakan 
warna dari VCO yang mengandung karotenoid wortel. Sabun yang dibuat ini mengandung karotenoid yang diduga baik untuk kulit. VCO yang dihasilkan ini direaksikan dengan $\mathrm{NaOH}$ pada beberapa konsentrasi, yaitu 25\%, 30\%, 35\%, dalam wadah berbeda. Perbandingan massa air dan massa $\mathrm{NaOH}$ untuk membuat masing-masing konsentrasi larutan $\mathrm{NaOH}$ disajikan pada Tabel 1.

Tabel 1 - Massa air dan massa $\mathrm{NaOH}$ untuk setiap konsentrasi $\mathrm{NaOH}$.

\begin{tabular}{|c|c|c|c|}
\hline No. & Konsentrasi NaOH & Massa NaOH & Massa Air \\
\hline 1. & $25 \%$ & 3,46 gram & 10,40 gram \\
\hline 2. & $30 \%$ & 3,46 gram & 8,08 gram \\
\hline 3. & $35 \%$ & 3,46 gram & 6,43 gram \\
\hline
\end{tabular}

\subsection{Kualitas Sabun Mandi Padat berdasarkan Uji SNI}

Tabel 2 menyajikan data hasil uji SNI terhadap sabun mandi padat dari VCO mengandung karotenoid wortel dan nilai SNI-nya.

\subsection{Kadar Air}

Berdasarkan hasil penelitian bahwa kadar air untuk sabun dengan konsentrasi $\mathrm{NaOH} 25 \%$ dan 30\% sudah melampaui kadar air maksimal yang direkomendasikan menurut SNI (Tabel 2). Sebaliknya pada konsentrasi $\mathrm{NaOH} 35 \%$, kadar air sesuai dengan standar yang ditetapkan. Hasil analisis pada Tabel 2 menunjukkan bahwa makin tinggi konsentrasi $\mathrm{NaOH}$ yang digunakan, maka kadar air dalam sabun makin rendah, karena semakin sedikit air yang digunakan. Semakin banyak air yang terkandung dalam sabun maka sabun akan semakin mudah menyusut saat digunakan (Spitz, 1996). Sabun yang memenuhi kriteria sabun mandi SNI ialah pada konsentrasi $\mathrm{NaOH} 35 \%$.

\subsection{Jumlah Asam Lemak}

Sabun yang baik memiliki total asam lemak dengan nilai lebih besar dari 70\%, artinya bahanbahan yang di-tambahkan sebagai bahan pengisi (bahan aditif) dalam pembuatan sabun sebaiknya kurang dari 30\%. Jumlah asam lemak untuk sabun dengan konsentrasi $\mathrm{NaOH} 25 \%, 30 \%$, 35\% memenuhi kualitas menurut SNI untuk sabun mandi padat, karena lebih besar dari 70\% (Tabel 2). Sabun mandi untuk ketiga konsentrasi bisa disimpan dalam waktu yang lama serta sangat efisien dalam membersihkan kotoran (William and Schmidt, 2002).

\subsection{Alkali Bebas}

Kadar alkali bebas sabun mandi padat dalam penelitian ini memenuhi standar menurut SNI 063532-1994. Kadar alkali bebas tertinggi adalah $0,044 \%$ pada sabun dengan konsentrasi $\mathrm{NaOH} 25 \%$, tetapi masih memenuhi standar mutu SNI, yakni kurang dari $0,1 \%$ untuk $\mathrm{NaOH}$ Alkali bebas adalah alkali dalam sabun yang tidak terikat dengan asam lemak membentuk garam asam lemak (sabun). Alkali dalam sabun mandi tidak boleh melebihi 0,1\% untuk natrium, karena alkali memiliki sifat yang keras dan dapat mengakibatkan iritasi pada kulit. Bila kadar alkali bebas terlalu tinggi, akan menyebabkan kulit menjadi kering (Hernani et al., 2010).

\subsection{Asam Lemak Bebas}

Asam lemak bebas dalam sabun mandi yang dibuat pada semua konsentrasi $\mathrm{NaOH}$ memenuhi stadar mutu menurut SNI. Standar mutu SNI untuk kadar asam lemak bebas sabun mandi padat adalah kurang dari 2,5\% (Tabel 2).

Tabel 2 - Perbandingan kualitas sabun mandi mengandung karotenoid wortel dengan SNI.

\begin{tabular}{|l|l|c|c|c|c|c|c|}
\hline \multirow{2}{*}{ No Uraian } & \multicolumn{3}{|c|}{ SNI } & \multicolumn{3}{c|}{ Sabun Mandi } \\
\cline { 3 - 8 } & & Tipe 1 & Tipe 2 & Seperfat & $25 \%$ & $30 \%$ & $35 \%$ \\
\hline 1 & Kadar Air(\%) & Maks 15 & Maks 15 & Maks 15 & 19,4 & 16,23 & 14 \\
\hline 2 & Jumlah Asam Lemak (\%) & $>70$ & $64-70$ & $>70 \%$ & 74,08 & 75,07 & 76,09 \\
\hline 3 & Alkali bebas (\%) & Max 0,1 & Max0,1 & Max 0,1 & 0,044 & - & - \\
\hline 4 & Asam Lemak Bebas (\%) & $<2,5$ & $<2,5$ & $<2,5$ & 1,6365 & 1,167 & 1,767 \\
\hline 5 & Lemak Netral (\%) & $<2,5$ & $<2,5$ & $<2,5$ & 9,760 & 9,952 & 10,278 \\
\hline
\end{tabular}

\subsection{Lemak Yang Tidak Tersabunkan}

Lemak yang tidak tersabunkan pada sabun dengan konsentrasi $\mathrm{NaOH} 25 \%$ adalah 9,76\%, konsentrasi $30 \%$ adalah 9,952\%, dan konsentrasi $35 \%$ adalah 10,278\%(Tabel 2). Standar mutu menurut SNI untuk lemak yang tidak tersabunkan adalah 2,5\%. Sabun mandi padat untuk semua konsentrasi $\mathrm{NaOH}$ telah melebihi standar mutu menurut SNI dan hasil ini menunjukan bahwa lemak netral atau trigliserida pada sabun mandi padat yang tidak bereaksi selama proses penyabunan relatif tinggi, sehingga tidak memenuhi SNI. Tingginya lemak yang tidak tersabunkan dalam sabun pada penelitian ini dapat disebabkan oleh komponen senyawa yang tak tersabunkan seperti kandungan senyawa karotenoid yang terlarut dalam VCO yang digunakan. Hasil ini sejalan dengan penelitian Brown et al. (2011) 
yang melaporkan bahwa pada proses pembuatan sabun terdapat komponen-komponen dari lemak dan minyak yang tidak dapat tersabunkan oleh perlakuan kaustik biasa. Komponen yang tidak tersabunkan tersebut di antaranya adalah alkohol berantai panjang, pigmen-pigmen, sterol, minyak-minyak mineral dan hidrokarbon.

\subsection{Minyak Mineral}

Hasil penelitian menunjukkan bahwa pada konsentrasi $\mathrm{NaOH}$ 25\% dan 35\% minyak mineral positif ada karena ditunjukkan dengan kekeruhan, sedangkan untuk konsentrasi $\mathrm{NaOH} 30 \%$ negatif karena hasil setelah dititrasi dengan air warna larutan bening (Tabel 2). Berdasarkan standar mutu menurut SNI, minyak mineral dalam sabun mandi padat seharusnya tidak lebih dari 0,05\%, yang ditandai dengan tidak adanya kekeruhan saat dititrasi dengan air. Pada penelitian ini, sabun mandi yang memenuhi standar menurut SNI adalah sabun dengan konsetrasi $\mathrm{NaOH}$ 30\% sabun dengan konsentrasi $\mathrm{NaOH}$ 25\% dan 35\% tidak memenuhi SNI. Adanya minyak mineral diduga dapat diakibatkan dekarboksilasi asam lemak menjadi golongan alkana. Dekarboksilasi dapat dilakukan secara termal, fotokimia, ataupun secara katalitik dengan bantuan katalis. Baik asam rantai terbuka dan aromatik dapat mengalami reaksi dekarboksilasi (Setiadi \& Suranto A, 2010).

\section{Kesimpulan}

Penelitian ini menyimpulkan bahwa VCO yang mengandung karotenoid wortel dapat digunakan dalam pembuatan sabun mandi padat. Bilangan penyabunan untuk menyabunkan 1 gram VCO yang mengandung karotenoid wortel adalah 173,18 miligram $\mathrm{NaOH}$. Konsentrasi $\mathrm{NaOH}$ yang optimal untuk menghasilkan sabun mandi padat dari VCO mengandung karotenoid wortel belum ada yang memenuhi standar SNI. Konsentrasi $\mathrm{NaOH}$ yang mendekati kualitas sesuai SNI No. 06-3532-1994 adalah 30\% dan 35\%.

\section{Daftar Pustaka}

Andarwulan, N., Koswara, S. Kimia Vitamin. Rajawali Pers, Jakarta. 1992.

Badan Standarisasi Nasional. Standar Nasional Indonesia (SNI). Sabun Mandi Padat. 1994. SNI.

Brown, H. J., Copeland, L. R., Kleiman R., Cummings, M. K., Koritala, S., Manoramarao, K.. High Unsaponifiables and Methods of Using The Same. 2011. United States Patent Application Pubblication: US2011/0293544 A1.

Hernani, Bunasor K. T., dan Fitriati. Formula Sabun Transparan Antijamur dengan Bahan Aktif Ekstrak Lengkuas (Alpinia Galanga L.Swartz.). Bul. Littro. 2010. 21 (2),192 - 205.

Makalalag, E. Aktivitas Antioksidan Ekstrak Wortel Yang Ditambahkan dalam Proses Pembuatan Minyak Kelapa Murni. 2010. Skripsi, FMIPA Universitas Sam Ratulangi, Manado.

Setiadi, Suranto A,. Reaksi Dekarboksilasi Minyak Jarak Pagar untuk Pembuatan Hidrokarbon Setara Fraksi Diesel Dengan Penambahan $\mathrm{Ca}(\mathrm{OH})_{2}$. HIm: 1-8. Prosiding Seminar Nasional Teknik Kimia Indonesia; Bandung. 19-20 Oktober 2009.

Spitz, L. Soap and Detergent a Theoritical and Practical Review. AOCS Press. Champaign-Illinois. 1996.

Williams, D. F., Schmitt, W. H. Kimia dan Teknologi Industri Kosmetika dan Produk-Produk Perawatan Diri. Terjemahan. FATETA, IPB, Bogor. 2002 